\title{
Perioperative outcomes of cardiac surgery in kidney and kidney-pancreas transplant recipients
}

Ranjit John, MD, Katherine Lietz, MD, Stephen Huddleston, MD, Arthur Matas, MD, Kenneth Liao, MD, Sara Shumway, MD, Lyle Joyce, MD, and R. Morton Bolman, MD

From the Division of Cardiothoracic Surgery, Department of Surgery, University of Minnesota, Minneapolis, Minn.

Supported by NIH-DK 13083.

Read at the Thirty-second Annual Meeting of the Western Thoracic Surgical Association, Sun Valley, Idaho, June 21-24, 2006.

Received for publication June 22, 2006; revisions received Nov 15, 2006; accepted for publication Nov 28, 2006.

Address for reprints: Ranjit John, MD, Assistant Professor, Division of Cardiothoracic Surgery, University of Minnesota, Minneapolis, MN 55455 (E-mail: johnx008@ umn.edu).

J Thorac Cardiovasc Surg 2007;133:1212-9

$0022-5223 / \$ 32.00$

Copyright $\odot 2007$ by The American Association for Thoracic Surgery

doi:10.1016/j.jtcvs.2006.11.041
Objective: Cardiovascular disease is a common cause of morbidity and mortality in organ transplant recipients, and cardiac surgery has become more common in this population. We performed a retrospective study of kidney transplant recipients who underwent cardiac surgery over the past 10 years at our institution with an emphasis on evaluating postoperative outcomes.

Methods: Seventy-four patients with previous abdominal transplants underwent cardiac surgery (93\% coronary artery bypass grafting, 5.4\% bypass grafting plus valve, and 1.4\% valve) between 1995 and 2005. These recipients were compared with 895 adult nontransplant patients undergoing cardiac surgery between 2000 and 2005. Only kidney and kidney-pancreas recipients were included in the analysis $(n=70)$ because there were only 2 liver and pancreas alone transplants.

Results: As compared with nontransplant patients, kidney transplant patients were younger (mean age $52.1 \pm 10$ years vs $61 \pm 13$ years; $P<.001$ ) and had an increased incidence of diabetes $(92.9 \%$ vs $39.1 \% ; P<.001)$, peripheral vascular disease $(37.1 \%$ vs $19.1 \% ; P<.001)$, chronic kidney insufficiency $(73.0 \%$ vs $13.4 \%$; $P<0.001)$, and unstable angina $(44.8 \%$ vs $25.7 \% ; P=.005)$ There was no difference between the two groups in the complication rate at 30 days after surgery, except that transplant patients were more likely to have postoperative kidney dysfunction $(32.6 \%$ vs $6.1 \% ; P<.001)$ and require hemodialysis $(11.7 \%$ vs $1.1 \%$; $P<.0001)$. Thirty-day postoperative mortality was similar between groups $(1.4 \%$ vs $2.9 \% ; P=$ not significant). By multivariable analysis, preoperative congestive heart failure, nonelective surgery, prolonged cardiopulmonary bypass times, peripheral vascular disease, and lower creatinine clearance were significant risk factors for postoperative mortality; however, prior kidney transplant was not an independent risk factor for 30-day postoperative mortality.

Conclusions: Despite their increased incidence of comorbid conditions, the postoperative outcomes of cardiac surgery in kidney transplant recipients are similar to those in the nontransplant population except for a higher incidence of kidney dysfunction in transplant patients.

$\mathrm{T}$ he excellent long-term results of abdominal organ transplants are leading to wider applicability, especially in higher risk recipients including older candidates and those at risk for cardiac disease. As a consequence, more transplant recipients are being referred for the evaluation and treatment of cardiovascular disease and, in particular, coronary atherosclerosis.

In 1984, we ${ }^{1}$ first published our experience at the University of Minnesota with cardiac surgery in 14 kidney transplant recipients. Herein, we present our recent experience with cardiac surgery in a larger series of kidney transplant recipients. The objectives of this study were (1) to identify the characteristics and risk factors in kidney transplant recipients who underwent cardiac surgery and (2) to evaluate 


\section{Abbreviations and Acronyms \\ $\mathrm{CABG}=$ coronary artery bypass graft \\ $\mathrm{LVEF}=$ left ventricular ejection fraction \\ $\mathrm{RR} \quad=$ relative risk \\ $\mathrm{SCr}=$ serum creatine concentration}

their early mortality and morbidity and changes in kidney function as compared with nontransplant patients.

\section{Patients and Methods \\ Study Population}

A total of 74 abdominal organ transplant recipients (58 kidney, 12 combined kidney-pancreas, 2 pancreas, 2 liver) underwent cardiac surgery at the University of Minnesota Medical Center between January 1995 and October 2005. Of these 74 recipients, 73 underwent coronary artery bypass graft (CABG) surgery ( 5 with combined valve surgery), and 1 underwent valve surgery alone. Because of the small number of liver alone and pancreas alone transplants, they will not be included in our analysis. Of the 70 kidney transplant recipients, $38.6 \%$ had failed allografts and were on dialysis at the time of their cardiac surgery. We compared the outcomes of cardiac surgery in the 70 kidney transplant recipients with the outcome in 895 nontransplant patients who underwent cardiac surgery at out institution between January 2000 and February 2005. Of these 895 nontransplant patients, 699 underwent CABG surgery (102 with concomitant valve surgery) and 196 underwent valve surgery alone.

All patients were followed up until death or 30 days after surgery during the mean follow-up time of 29.5 days (range: $0-30$ ). We collected patient data from both the hospital medical records and the institutional data reported to the Society of Thoracic Surgeons Database. All patients provided informed consent and the registry was approved by our institutional review board.

\section{Clinical Data}

For all patients, we analyzed the following characteristics: presence of heart disease symptoms, presence or absence of chronic or unstable angina, physician-defined symptoms of decompensated heart failure, percutaneous coronary intervention, percentage of left ventricular ejection fraction (LVEF) at the time of surgery, presence of comorbidities, including diabetes, dyslipidemia, hypertension, history of stroke, peripheral vascular disease, renal function (serum creatinine concentration $[\mathrm{SCr}]$ serum creatinine clearance calculated from Cockroft-Gault equation, chronic hemodialysis), elective versus urgent surgery; crossclamp and perfusion times, and postoperative complications. These included cardiac complications, such as tamponade, myocardial infarction, reoperation for occlusion or other causes, requirement of intra-aortic balloon pump support, renal dysfunction defined as rise of $\mathrm{SCr}$ above $2.5 \mathrm{mg} / \mathrm{dL}$ and/or a need for hemodialysis, ventilatory support, pneumonia, multiorgan failure, gastrointestinal complications, leg infection, sepsis, coma, and neurologic complications, and readmission within 30 days after surgery.

\section{Preoperative Management}

Antibiotics. All patients received preoperative antibiotics before skin incision, including cephalosporins for CABG surgery and vancomycin for valve operations. Antibiotics were continued for at least 24 hours postoperatively, barring other clinical indications for longer duration of therapy.

Immunosuppression. Immunosuppressive protocols for our transplant recipients have been described in detail. ${ }^{2}$ Maintenance immunosuppression was not changed before cardiac surgery. Doses were held while patients were under nothing-by-mouth orders and restarted within 24 hours after surgery. If the recipient was not tolerating oral medications within 24 hours, intravenous doses were given. Dosing of calcineurin inhibitors was also held if there was significant postoperative kidney dysfunction. Immunosuppressive drug levels were monitored and adjusted when necessary. Prophylactic stress doses of corticosteroids were given to all patients receiving long-term steroid therapy.

\section{Cardiac Surgery}

In all patients, cardiac surgery was performed with standard surgical techniques through a median sternotomy using cardiopulmonary bypass with membrane oxygenation and moderate systemic hypothermia (temperature range, $28^{\circ} \mathrm{C}$ to $32^{\circ} \mathrm{C}$ ). In renal transplant recipients, a higher mean perfusion pressure was maintained to optimize kidney perfusion. Cold antegrade blood cardioplegia was used for all patients with retrograde blood cardioplegia in some patients for myocardial preservation. Anticoagulation was achieved before cardiopulmonary bypass with heparin $(300-400 \mathrm{U} / \mathrm{kg}$ ) to achieve activated clotting times greater than 400 seconds.

\section{Perioperative Care}

Standard intensive care unit protocols were used in the immediate postoperative care of these patients, including inotropic support with dopamine or milrinone. All patients had hemodynamic monitoring with a Swan-Ganz catheter (Edwards LifeSciences, Irvine, Calif) to closely monitor cardiac function and intravascular volume status.

Patients who were dialysis-dependent underwent their usual maintenance hemodialysis the day before surgery. During surgery, large-volume hemofiltration was carried out by the perfusion team during cardiopulmonary bypass. Additionally, these patients were closely followed up by the kidney service to determine the frequency and timing of postoperative dialysis, in conjunction with the cardiothoracic surgical team.

\section{Follow-up}

All patients were seen by the surgical team about 2 weeks after discharge. They were also routinely followed up by the appropriate transplant and cardiology services.

\section{Complications and Causes of Death}

Adverse events and causes of death were characterized by the attending physician. Autopsy results were not available.

\section{Statistical Analysis}

Differences between the two groups were examined by the $\chi^{2}$ or Fisher exact test. Continuous variables were compared by a Student $t$ test if normally distributed; if not, a Wilcoxon rank-sum test 
TABLE 1. Patient characteristics

\begin{tabular}{lccc}
\hline & $\begin{array}{c}\text { Nontransplant, } \\
\mathbf{n = 8 9 5}(\%)\end{array}$ & $\begin{array}{c}\text { Transplant, } \\
\mathbf{n}=\mathbf{7 0}(\%)\end{array}$ & $\boldsymbol{P}$ value \\
\hline Demographics & & & \\
Female gender & 31.8 & 28.6 & .57 \\
White ethnicity & 90.9 & 92.5 & .66 \\
Age $>50$ y & 79.0 & 41.4 & $<.001$ \\
Mean age + SD (y) & $61.0 \pm 13.6$ & $52.1 \pm 9.9$ & $<.001$ \\
Mean body mass & $28.7 \pm 5.9$ & $27.1 \pm 5.3$ & .01 \\
$\quad$ index (kg/m ${ }^{2}$ ) & & & \\
Comorbidities & & & \\
Diabetes & 39.1 & 92.9 & $<.001$ \\
Tobacco use & 50.8 & 38.6 & .05 \\
Dyslipidemia & 67.4 & 51.4 & .006 \\
Hypertension & 76.2 & 82.8 & .20 \\
History of strokes & 7.9 & 8.6 & .85 \\
Peripheral vascular & 19.1 & 37.1 & $<.001$ \\
$\quad$ disease & & & \\
\hline
\end{tabular}

was used. Survival estimates were based on the Kaplan-Meier method and compared with log-rank statistics. To identify preoperative risk factors for perioperative 30-day mortality after cardiac surgery, we entered parameters (Table 1) into our univariate analysis model. The covariates, which correlated with end points on univariate analysis at $P$ value $<.15$, were entered and allowed to stay in a stepwise multiple logistic regression model at a $P$ value of $<.15$. Values are reported as mean \pm standard deviation. All data were analyzed by the SAS system software version 9.0 (SAS Institute, Inc, Cary, NC).

\section{Results}

\section{Patient Characteristics}

The demographics of transplant recipients and control subjects undergoing cardiac surgery are shown in Table 1 . Transplant patients were predominantly white men with a mean age of 52.1 years. The majority of these patients had more than one major cardiovascular risk factor, were younger, had lower body mass index, were less likely to smoke or have dyslipidemia, but were more likely to have peripheral vascular disease We found no statistically significant differences between the two groups in regard to gender, ethnicity, prevalence of hypertension, or history of strokes (Table 1).

\section{Kidney Function}

The majority (68.6\%) of transplant recipients who underwent cardiac surgery had abnormal kidney function- $\mathrm{SCr}$ was greater than $2 \mathrm{mg} / \mathrm{dL}$ in $30 \%$ and $38.6 \%$ had returned to hemodialysis (Table 2). As compared with nontransplant patients, transplant recipients had significantly worse kidney function. Transplant recipients were also four times more likely to be receiving hemodialysis before their cardiac surgery.
TABLE 2. Kidney function

\begin{tabular}{|c|c|c|c|}
\hline & $\begin{array}{c}\text { Nontransplant, } \\
n=895 \\
\text { mean } \pm \text { SD (\%) }\end{array}$ & $\begin{array}{c}\text { Transplant, } \\
n=70 \\
\text { mean } \pm \text { SD (\%) }\end{array}$ & $P$ value \\
\hline Mean SCr (mg/dL) & $1.47 \pm 1.4$ & $3.73 \pm 2.4$ & $<.001$ \\
\hline $\begin{array}{l}\text { Mean SCr clearance } \\
\qquad\left(\mathrm{mL} \cdot \mathrm{kg}^{-1} \cdot \mathrm{min}^{-1}\right)\end{array}$ & $82.16 \pm 47.7$ & $38.6 \pm 27.2$ & $<.001$ \\
\hline \multicolumn{4}{|l|}{$\begin{array}{r}\text { Severity of renal } \\
\text { insufficiency }\end{array}$} \\
\hline $\begin{array}{l}\mathrm{SCr} \pm 2 \mathrm{mg} / \mathrm{dL}, \text { no } \\
\text { hemodialysis }\end{array}$ & 87.3 & 31.4 & $<.001$ \\
\hline $\begin{array}{c}\mathrm{SCr}>2 \mathrm{mg} / \mathrm{dL}, \text { no } \\
\text { hemodialysis }\end{array}$ & 5.1 & 30.0 & $<.001$ \\
\hline Hemodialysis & 7.6 & 38.6 & $<.001$ \\
\hline
\end{tabular}

$S C r$, Serum creatinine concentration.

TABLE 3. Clinical presentation

\begin{tabular}{lccc}
\hline & $\begin{array}{c}\text { Nontransplant, } \\
\mathbf{n}=\mathbf{8 9 5}, \\
\text { mean } \pm \text { SD (\%) }\end{array}$ & $\begin{array}{c}\text { Transplant, } \\
\mathbf{n}=\mathbf{7 0}, \\
\text { mean } \pm \text { SD (\%) }\end{array}$ & $\begin{array}{c}\boldsymbol{P} \\
\text { value }\end{array}$ \\
\hline Cardiac angina & & & \\
$\quad$ No angina & 31.8 & 47.1 & .008 \\
Chronic angina & 23.3 & 30 & .21 \\
Unstable angina & 25.7 & 22.8 & $<.001$ \\
Functional capacity & & & \\
NYHA class I & 4.6 & 1.7 & .31 \\
NYHA class II & 16.9 & 17.2 & .94 \\
NYHA class III & 57.2 & 60.3 & .63 \\
NYHA class IV & 21.4 & 20.7 & .90 \\
Congestive heart failure & 28.2 & 21.4 & .22 \\
History of myocardial & 39.8 & 37.1 & .66 \\
$\quad$ infarction & & & \\
Vascular intervention & 38.8 & 37.1 & .79 \\
$\quad$ with/without PTCA & & & \\
LVEF & & & .18 \\
LVEF $\leq 40 \%$ & 31.5 & 23.4 & .28 \\
Mean \% LVEF & $49.1+15.5$ & $51.2+12.6$ &
\end{tabular}

NYHA, New York Heart Association; PTCA, percutaneous transluminal coronary angioplasty; $L V E F$, left ventricular ejection fraction.

\section{Clinical Presentation}

At the time of cardiac surgery, $37 \%$ of kidney transplant recipients had symptoms of decompensated heart failure; New York Heart Association functional class III or IV was present in the majority (81\%) of patients; $23 \%$ of recipients had a mean LVEF of $40 \%$ or less (Table 3 ). There were no statistically significant differences between kidney transplant recipients and nontransplant recipients with regard to the prevalence of heart failure at time of surgery, New York Heart Association functional class distribution, history of myocardial infarction, percutaneous coronary vascular intervention, and mean LVEF (Table 3).

Unstable angina before cardiac surgery was less common in kidney transplant recipients than in nontransplant pa- 
TABLE 4. Thirty-day nonrenal complications

\begin{tabular}{lccc}
\hline & $\begin{array}{c}\text { Nontransplant, } \\
\mathbf{n = 8 9 5}(\%)\end{array}$ & $\begin{array}{c}\text { Transplant, } \\
\mathbf{n = 7 0}(\%)\end{array}$ & $\boldsymbol{P}$ value \\
\hline Prolonged ventilatory support & 18.3 & 11.4 & .14 \\
Leg infection & 2.0 & 2.9 & .63 \\
Sepsis & 1.7 & 2.9 & .47 \\
Myocardial infarction & 1.7 & 2.9 & .47 \\
Coma for $>$ 24 h & 1.1 & 2.9 & .21 \\
Neurologic & 2.3 & 1.4 & .62 \\
Multiorgan failure & 1.1 & 1.4 & .81 \\
Gastrointestinal & 4.7 & 1.4 & .20 \\
Pneumonia & 6.7 & 1.4 & .08 \\
Tamponade & 1.0 & 0 & .40 \\
Other & 30 & 20 & .15 \\
\hline
\end{tabular}

tients, and kidney transplant recipients more often presented without anginal symptoms as compared with nontransplant patients undergoing cardiac surgery.

\section{Cardiac Surgery}

The majority (98.5\%) of the 70 kidney transplant recipients underwent CABG surgery (with or without concomitant valve surgery) and $1.4 \%$ underwent valve surgery alone. Of these cardiac operations, most were elective. Only $8.6 \%$ of patients had a significant $(>50 \%)$ left main coronary artery lesion. For revascularization, the internal thoracic artery was used in $62.3 \%$ of those who underwent CABG surgery. As compared with 895 nontransplant patients, kidney transplant recipients were more likely to undergo elective surgery ( $68.6 \%$ vs $55.9 \% ; P=.04)$, more likely to undergo CABG surgery rather than valve surgery alone $(98.5 \%$ vs $78.1 \% ; P=.002)$, less likely to have significant left main coronary disease ( $8.6 \%$ vs $18 \% ; P=.04)$, and less likely to have the internal thoracic artery graft for revascularization $(62.3 \%$ vs $88.3 \% ; P<.001)$. Transplant recipients also had shorter crossclamp time $(95.3+46.3$ minutes vs $112.7 \pm$ 52 minutes; $P=.009)$ and shorter perfusion time (141.3+ 54.8 minutes vs $160+68.4$ minutes; $P=.01$ ).

\section{Outcomes of Cardiac Surgery}

Nonrenal complications. During the first 30 postoperative days, nearly half (47\%) of transplant recipients who underwent cardiac surgery had at least one postoperative nonrenal complication. The most common included need for ventilatory support (11.4\%), systemic infection or sepsis (2.9\%), postoperative myocardial infarction $(2.9 \%)$, neurologic complication or coma (2.9\%), pneumonia (1.4\%), multiorgan failure (1.4\%), gastrointestinal complications (1.4\%), and limb ischemia (1.4\%) (Table 4).

However, there was no significant difference between transplant and nontransplant recipients in the incidence of nonrenal postoperative complications. There was a trend
TABLE 5. Thirty-day outcomes

\begin{tabular}{|c|c|c|c|}
\hline & $\begin{array}{c}\text { Nontransplant, } \\
n=895(\%)\end{array}$ & $\begin{array}{l}\text { Transplant, } \\
\mathrm{n}=70(\%)\end{array}$ & $\begin{array}{c}P \\
\text { value }\end{array}$ \\
\hline Reoperation & 4.7 & 2.9 & .48 \\
\hline Vessel occlusion & 0.7 & 1.4 & .47 \\
\hline Other causes & 2.1 & 0 & .21 \\
\hline \multicolumn{4}{|l|}{ Survival } \\
\hline 30-day survival & 97.1 & 98.6 & .47 \\
\hline No. of deaths & $26 / 894$ & $1 / 70$ & \\
\hline Causes of death & $\begin{array}{l}\text { Cardiac }(n=20) \\
\text { CVA or neurologic } \\
(n=4) \text {, renal }(n=1) \text {, } \\
\text { and pulmonary }(n=1)\end{array}$ & $\operatorname{CVA}(\mathrm{n}=1)$ & \\
\hline
\end{tabular}

CVA, Cerebrovascular accident.

toward higher incidence of postoperative pneumonia in nontransplant patients.

Kidney dysfunction. The likelihood of postoperative kidney dysfunction developing within 30 days after surgery was higher in transplant than nontransplant recipients. Among patients who were not hemodialysis-dependent at the time of surgery, postoperative kidney dysfunction defined by a need for hemodialysis or a rise of $\mathrm{SCr}$ greater than $2 \mathrm{mg} / \mathrm{dL}$ developed in $32.6 \%$ of transplant recipients (14/43) as compared with $6 \%$ of nontransplant patients (50/827) $(P<.001)$.

The likelihood that kidney allograft function would worsen after cardiac surgery correlated with the baseline preoperative $\mathrm{SCr}$. In transplant patients with $\mathrm{SCr}$ greater than $2 \mathrm{mg} / \mathrm{dL}, 47.6 \%(10 / 21)$ had a postoperative $\mathrm{SCr}$ elevation versus $18.2 \%(4 / 22)$ of those with preoperative $\mathrm{SCr}$ of $2 \mathrm{mg} / \mathrm{dL}$ or less $(P=.04)$. Similar trends were observed in nontransplant patients; of those with baseline $\mathrm{SCr}$ greater $2 \mathrm{mg} / \mathrm{dL}, 21.7 \%$ (10/46) had a postoperative $\mathrm{SCr}$ rise versus $5 \%(40 / 781)$ of patients with baseline $\mathrm{SCr}$ of $2 \mathrm{mg} / \mathrm{dL}$ or less $(P<.001)$.

Long-term kidney function. Of the 14 transplant patients who had postoperative kidney dysfunction (defined as a need for hemodialysis or a rise of $\mathrm{SCr}>2 \mathrm{mg} / \mathrm{dL}$ ), 3 required temporary hemodialysis and 11 had a rise in $\mathrm{SCr}$ greater than $2 \mathrm{mg} / \mathrm{dL}$. The 3 who required hemodialysis all regained kidney function and were alive at 5 years of follow-up with a functioning allograft. Of the 11 patients with a rise in $\mathrm{SCr}$ greater than $2 \mathrm{mg} / \mathrm{dL}, 4$ lost allograft function 1 year after cardiac surgery and required permanent hemodialysis; of the remaining 7,1 died within 1 year, but 6 were alive at 5 years of follow-up with a functioning allograft. Thus, the overall 5-year dialysis-free survival of transplant recipients in whom kidney dysfunction developed after cardiac surgery was $64.2 \%(9 / 14)$.

Reoperation and readmission. Overall, only $8.6 \%$ of transplant recipients required cardiac reoperation (including for bleeding) and $8.6 \%$ of patients required readmission 
TABLE 6. Risk factors for 30-day mortality after cardiac surgery $(n=965)$

\begin{tabular}{|c|c|c|c|c|}
\hline & Univariate analysis & $P$ value & Multivariate analysis & $P$ value \\
\hline Perfusion time (min) & $8.78(3.47-22.2)$ & $<.001$ & $7.18(2.68-19.19)$ & $<.001$ \\
\hline Symptoms of CHF & $6.62(2.86-15.3)$ & $<.001$ & $3.47(1.26-9.58)$ & $<.001$ \\
\hline Nonelective surgery & $3.90(1.63-9.32)$ & .001 & $3.33(1.24-8.90)$ & .002 \\
\hline Peripheral vascular disease & $2.78(1.27-6.08)$ & .008 & $2.95(1.22-7.1)$ & .006 \\
\hline LVEF $\leq 40 \%$ & $4.70(2.09-10.6)$ & $<.001$ & $2.89(1.08-7.73)$ & .04 \\
\hline $\mathrm{SCr} \mathrm{Cl}<60 \mathrm{~mL} \cdot \mathrm{kg}^{-1} \cdot \min ^{-1}$ & $2.16(0.99-4.72)$ & .05 & $2.27(0.93-5.59)$ & .07 \\
\hline Clamp time (min) & $4.00(1.75-9.18)$ & $<.001$ & & \\
\hline Hypertension & $3.91(0.92-16.6)$ & .05 & & \\
\hline Coronary intervention & $2.78(1.26-6.15)$ & .008 & & \\
\hline Female gender & $1.76(0.81-3.80)$ & .15 & & \\
\hline
\end{tabular}

$C H F$, Congestive heart failure; $L V E F$, left ventricular ejection fraction; $S C r C l$, Serum creatinine clearance.

within 30 days after surgery. There were no differences in the incidence of cardiac reoperation between transplant and nontransplant patients (Table 5). However, there was a nonsignificant trend toward lower rates of readmission in transplant patients $(8.6 \%$ vs $15.1 \% ; P=.14)$.

Thirty-day mortality after cardiac surgery. The 30-day postoperative mortality rate did not differ between transplant and nontransplant patients. Of the transplant recipients who underwent cardiac surgery, 1 died within 30 days postoperatively (cerebrovascular accident) (Table 5). Cardiac complications were the main causes of postoperative deaths in nontransplant patients (Table 5).

Risk factors for 30-day mortality. Using multivariate analysis, we identified the following factors to be significant predictors for 30-day mortality: perfusion time greater than 180 minutes (relative risk $[\mathrm{RR}]=7.18 ; P<.001$ ), symptoms of congestive heart failure $(\mathrm{RR}=3.47 ; P<.001)$, urgent or emergency cardiac surgery versus elective surgery $(\mathrm{RR}=3.33 ; P=.002)$, and LVEF less than $40 \%$ at time of surgery $(\mathrm{RR}=2.89 ; P=.04)$ (Table 6). Additionally, a trend toward increased risk of 30-day mortality was seen in patients with a history of peripheral vascular disease $(\mathrm{RR}=$ $2.95 ; P=.06)$ and those with $\mathrm{SCr}$ clearance less than $60 \mathrm{~mL}$ $\cdot \mathrm{kg}^{-1} \cdot \min ^{-1}(\mathrm{RR}=2.27 ; P=.07)$. Importantly, a previous kidney transplant was not an independent risk factor for 30-day postoperative mortality.

\section{Discussion}

Cardiovascular disease is a major risk factor for adverse events in kidney and kidney-pancreas transplant recipients. Patients with end-stage renal disease are especially at high risk for death from cardiac causes. ${ }^{3,4}$ Between 1997 and1999, the death rate for US dialysis patients was 239 per 1000 patient-years, and cardiac disease accounted for $44 \%$ of all causes of death. ${ }^{5}$ In a retrospective study of 2694 adult kidney transplant recipients at the University of Minnesota, the overall incidence of adverse cardiovascular events, including myocardial infarction, within 30 days after transplant was $6.1 \% .^{6}$
In addition to the short-term risks, cardiovascular events are the most common cause of death with functioning kidney allografts. In a study of our recipient population, $17 \%$ of deaths in kidney transplant recipients with functioning grafts were due to myocardial infarction and $15 \%$ were due to sudden death (presumably due to arrhythmias). ${ }^{7}$ Kidney transplant recipients are at markedly increased risk for cardiovascular disease for numerous reasons. ${ }^{8}$ For many recipients (eg, those with diabetes or hypertension), the primary disease itself is associated with increased cardiovascular risk. In other recipients hypertension, hyperlipidemia, and hyperhomocysteinemia develop in association with kidney failure. Excess risk also may be due to the hemodynamic and metabolic factors that occurred during the pretransplant interval of chronic renal insufficiency $(\mathrm{eg}$, anemia, proteinuria, increased extracellular volume, electrolyte imbalance, and higher levels of thrombogenic factors). ${ }^{9}$ Patients in kidney failure are at higher risk for mitral and aortic valve calcification, as well as for coronary artery calcification. ${ }^{10}$ Postransplant hyperlipidemia, diabetes, and hypertension related to immunosuppressive regimens continue to place these recipients at increased risk. ${ }^{11}$

Reports show that simultaneous kidney-pancreas transplantation prolongs the survival of patients with end-stage renal disease as compared with kidney transplantation alone, possibly by decreasing cardiac causes of death. ${ }^{12}$ Several studies have shown that the presence of a functioning pancreas graft has favorable effects on lipid profiles, reduces the progression of coronary atherosclerosis, improves cardiac function, and reduces death rates from cardiovascular causes when compared with kidney-alone transplant recipients. ${ }^{13-15}$ Patients after liver transplant, a group without the traditional risk factors for cardiovascular disease as seen in kidney transplant recipients, have a greater than $10 \%$ incidence of adverse cardiovascular events after transplantation. ${ }^{16}$ Thus, it is not surprising that recipients of solid organ abdominal transplants have a high incidence of cardiovascular disease, often necessitating cardiac surgery. 
A transplant recipient is considered to be a high-risk candidate for cardiac surgery because of numerous risk factors, including coexisting immunosuppression (including long-term steroid use with its attendant complications), the inherent possibility of other end-organ dysfunction, and varying degrees of primary allograft dysfunction. In addition, cardiac surgery itself could adversely affect graft function and possibly lead to graft loss. Our current study found that 30-day mortality and morbidity rates were similar in transplant recipients and nontransplant patients. Smaller singlecenter studies have similarly reported low mortality after cardiac surgery in kidney transplant recipients. ${ }^{17-22}$ However, a large study from the United States Renal Data System database involving 1100 kidney transplant recipients undergoing CABG reported an in-hospital mortality rate of $5.0 \%$ with and $9.4 \%$ without internal thoracic artery use. ${ }^{23}$ Despite the higher mortality rates noted in this study, long-term survival was better after surgical revascularization than after percutaneous coronary intervention.

In our current study, we noted low rates of re-exploration for bleeding in transplant versus nontransplant patients. This low rate may be due to the use of dialysis on the day before surgery as well as hemofiltration during cardiopulmonary bypass. The beneficial effect of aprotinin on postoperative bleeding must be balanced in view of the recently reported adverse kidney effects in patients having cardiac surgery. ${ }^{24}$ Even though we did not use off-pump approaches for coronary revascularization in this experience, this technique has theoretical benefits of reduced incidence of bleeding and neurologic complications. ${ }^{25}$ Some studies have suggested, however, that off-pump surgery could be associated with incomplete coronary revascularization and reduced graft patency, and the need for and the risk-benefits of this approach must be decided on an individual basis. ${ }^{26,27} \mathrm{~A}$ recent large study also reported a morbidity and mortality benefit with the use of off-pump CABG in patients undergoing dialysis. ${ }^{28}$

Of note, increasing evidence supports the short- and long-term morbidity and mortality benefits of maintaining normoglycemia in patients undergoing $\mathrm{CABG}^{29}$ In the past 5 years, in all of our cardiac patients, we have established strict blood sugar control protocols, which may have helped keep our morbidity rates low. In contrast to our low morbidity rate, our increased incidence of postoperative kidney dysfunction in the transplant recipients was alarming. In both our study and others, preoperative kidney insufficiency was a significant risk factor for postoperative kidney failure. In patients with preoperative kidney insufficiency, the incidence of acute allograft failure is as high as $30 \% .{ }^{21}$ Our high incidence of kidney complications leaves much room for improvement. One study reports a lower incidence of kidney dysfunction in kidney transplant patients who had offpump coronary revascularization. ${ }^{21}$ Improved strategies with the use of possible kidney protective agents during cardiopulmonary bypass are necessary to reduce the morbidity associated with postoperative kidney dysfunction.

Most patients who have kidney dysfunction after cardiac surgery, including those who require temporary hemodialysis, will have return of allograft function. Encouragingly, our study showed that $64.2 \%$ of such patients were alive and dialysis-free 5 years after cardiac surgery. Aggressive attempts to preserve kidney function, avoidance of nephrotoxic medications, and the continued involvement of the kidney transplant team are imperative to allow for maximal return of function.

Our study has all the limitations inherent to a retrospective study. In addition, although results on early morbidity and short-term survival are important, longer-term follow-up would be valuable, including data on graft patency and freedom from valve degeneration. A significant proportion of our transplant recipients were already receiving hemodialysis, raising the question of whether or not these patients should be included in the transplant cohort. We included them because, even though they had graft failure and were receiving hemodialysis, it is our practice to keep them on maintenance immunosuppression.

In conclusion, our study provides useful data on the patient characteristics and on postoperative morbidity and mortality. It represents the largest single-center report of cardiac surgery in kidney and kidney-pancreas transplant recipients. Although the transplant recipients had an increased incidence of preoperative high risk factors, their postoperative mortality was low. Importantly, our multivariable analysis showed that a previous kidney transplant was not a risk factor for increased mortality after cardiac surgery.

We thank Mary E. Knatterud, PhD, for editorial assistance.

\section{References}

1. Bolman RM, Anderson RW, Molina JE, Schwartz JS, Levine B, Simmons RL, et al. Cardiac operations in patients with functioning renal allografts. J Thorac Cardiovasc Surg. 1984;88:537-43.

2. Moss A, Najarian JS, Sutherland DE, Payne WD, Gruessner RWG, Humar A, et al. 5000 kidney transplants-a single center experience. In: Clinical transplants 2000. Cecka JM, Terasaki PI, editors. Los Angeles: UCLA Immunogenetics Center; 2001.

3. Manske CL, Wilson RF, Want Y, Thomas W. Prevalence of, and risk factors for, angiographically determined coronary artery disease in type-I diabetic patients with nephropathy. Arch Int Med. 1992;152: 2450-5.

4. Herzog CA, Ma JZ, Collins AJ. Poor long-term survival after acute myocardial infarction among patients on long-term dialysis. $\mathrm{N} \mathrm{Engl}$ J Med. 1998;339:799-805.

5. US Renal Data System. USRDS 2001 annual data report. National Institutes of Health, National Institutes of Diabetes and Digestive and Kidney Diseases; 2001.

6. Humar A, Kerr SR, Ramcharan T, Gillingham KJ, Matas AJ. Perioperative cardiac morbidity in kidney transplant recipients: incidence and risk factors. Clin Transplant. 2001;15:154-8. 
7. West M, Sutherland DER, Matas AJ. Kidney transplant recipients who die with functioning grafts: serum creatine level and cause of death. Transplantation. 1996;15:1029-32.

8. Matas AJ, Humar A, Gillingham KJ, Payne WD, Gruessner RWG, Kandaswamy R, et al. Five preventable causes of kidney graft loss in the 1990s: a single center analysis. Kidney Int. 2002;62:704-14.

9. Levey AS, Beto JA, Coronado BE, Eknoyan G, Foley RN, Kasiske $\mathrm{BL}$, et al. Controlling the epidemic of cardiovascular disease in chronic renal failure: what do we know? What do we need to learn? Where do we go from here? Am J Kidney Dis. 1998;32:853-906.

10. Goodman WG, Golden J, Kuizon BD, Yoon C, Gales B, Sider D, et al. Coronary-artery calcification in young adults with end-stage renal disease who are undergoing dialysis. $N$ Engl J Med. 2000;342:1478-83.

11. Opelz G, Wujciak T, Ritz E. Association of chronic kidney graft failure with recipient blood pressure. Collaborative transplant study. Kidney Int. 1998;53:217-22.

12. Reddy KS, Stablein D, Taranto S, Stratta RJ, Johnston TD, Waid TH, et al. Long-term survival following simultaneous kidney-pancreas transplantation versus kidney transplantation alone in patients with type 1 diabetes mellitus and renal failure. Am J Kidney Dis. 2003;41:

13. Jukema JW, Smets YFC, Van Der Pijl JW, Zwinderman AH, Vliegen HW, Ringers J, et al. Impact of simultaneous pancreas and kidney transplantation on progression of coronary atherosclerosis in patients with end-stage renal failure due to type 1 diabetes. Diabetes Care. 2002;25:906-11.

14. La Rocca E, Fiorina P. Di Carlo V, Astorri E, Rossetti C, Lucignani G, et al. Cardiovascular outcomes after kidney-pancreas and kidney-alone transplantation. Kidney Int. 2001;60:1964-71.

15. Larsen J, Larsen C, Hirst K, Miller SA, Ozaki CF, Taylor RJ, et al. Lipid status after combined pancreas-kidney transplantation and kidney transplantation alone in type 1 diabetes mellitus. Transplantation. 1992;54:992-6.

16. Abbasoglu O, Levy MF. Cardiovascular events following liver transplantation. N Dev Transplant Med. 1995;2:9-10.

17. Ono M, Wolf RK, Angouras DC, Brown DA, Goldstein AH, Michler RE. Short- and long-term results of open heart surgery in patients with abdominal solid organ transplant. Eur J Cardiothorac Surg. 2002;21: 1061-72.

18. Mitruka SN, Griffith BP, Kormos RL, Hattler BG, Pigula FA, Shapiro $\mathrm{R}$, et al. Cardiac operations in solid-organ transplant recipients. Ann Thorac Surg. 1997;64:1270-8.

19. Reddy SV, Chen AS, Johnson HK, Pierson RN, Christian KJ, Drinkwater DC, et al. Cardiac surgery after renal transplantation. Am Surg. 2002;68:154-8

20. Massad MG, Kpodonu J, Lee J, Espat J, Gandhi S, Tevar A, et al. Outcome of coronary artery bypass operations in patients with renal insufficiency with and without renal transplantation. Chest. 2005;128: $855-62$.

21. Zhang L, Garcia JM, Hill PC, Haile E, Light JA, Corso PJ. Cardiac surgery in renal transplant recipients: experience from Washington Hospital Center. Ann Thorac Surg. 2006;81:1379-84.

22. Ferguson ER, Hudson SL, Diethelm AG, Pacifico AD, Dean LS, Holman WL. Outcome after myocardial revascularization and renal transplantation. A 25-year single-institution experience. Ann Surg. 1999;230:232-41.

23. Herzog CA, Ma JZ, Collins AJ. Long-term outcome of renal transplant recipients in the United States after coronary revascularization procedures. Circulation. 2004;109:2866-71.

24. Mangano DT, Tudor IC, Dietzel C, Multicenter Study of Perioperative Ischemia Research Group; Ischemia Research and Education Foundation. The risk associated with aprotinin in cardiac surgery. $N$ Engl J Med. 2006;354:353-65.

25. Mack M, Bachand D, Acuff T, Edgerton J, Prince S, Dewey T, et al. Improved outcomes in coronary artery bypass surgery with beating heart techniques. J Thorac Cardiovas Surg. 2002;124:598-607.

26. Khan NE, DeSouza A, Mister R, Flather M, Claque J, Davies S, et al. A randomized comparison of off-pump and on-pump multivessel coronary artery bypass surgery. $N$ Engl J Med. 2004;350:21-8.

27. Jones EL, Weintraub WS. The importance of completeness of revascularization during long-term follow-up after coronary artery operations. J Thorac Cardiovasc Surg. 1996;112:227-37.
28. Beckermann J, Van Camp J, Li S, Wahl SK, Collins A, Herzog CA. On-pump versus off pump coronary surgery outcomes in patients requiring dialysis: perspectives from a single center and the United States experience. J Thorac Cardiovasc Surg. 2006;131:1261-6.

29. Furnary AP, Gao G, Grunkemeir GL, Wu Y, Zerr KJ, Bookin SO, et al. Continuous infusion of insulin reduces mortality in patients undergoing coronary artery bypass grafting. J Thorac Cardiovasc Surg. 2003;125: 1007-21.

\section{Discussion}

Dr Patricia Thistlethwaite (San Diego, Calif). The strength and breadth of solid organ transplantation at the University of Minnesota have allowed for the creation of one of the largest groups of transplant patients for the study of cardiovascular disease.

With data from the United Network for Organ Sharing suggesting that kidney transplant patients survive on the average between 10 and 23 years depending on whether the organ was from a deceased or living donor and 25 years plus for an HLA identically matched donor, and with long-term survivals for kidney-pancreas transplants approaching 10 to 20 years, it is not surprising that cardiac disease is developing in these individuals over time. It is reassuring to see actual data about the safety of cardiac surgery in patients with transplant allografts.

I have the following questions. What is the effect of immunosuppression on wound healing in cardiac surgery? Were the people who had wound complications in your group receiving higher doses of prednisone or FK506? Did infection develop in any patients who were on a steroid-free protocol? Should patients be tapered down or off steroids before their cardiac operation?

Dr John. Clearly the presence of immunosuppression did not affect the incidence of mediastinal and leg wound infection or multiorgan sepsis; however, an important immunosuppressant that clearly affects wound healing is rapamycin. We do not have much experience with this agent because none of these patients was receiving it. However, that clearly is one immunosuppressive agent that has been shown to markedly increase the risk of wound dehiscence and multiple problems related to wound healing. All these patients were on immunosuppression. I do not have the data as to whether any of these patients were off steroids, but clearly with the low incidence of wound infection in both groups I would speculate that the presence of immunosuppression has not adversely affected wound healing.

Dr Thistlethwaite. During cardiac surgery should all solid organ transplant patients be treated the same? For example, do you modify perfusion pressure for individuals with worse organ function, and would you suggest the routine use of aprotinin during cases?

Dr John. My personal bias over the past 3 or 4 years has been to use aprotinin with even mild to moderate degrees of renal failure, maybe again based on some of the data to reduce the dose of aprotinin if the creatinine concentration was increased. In view of the recent report that all of us are aware of, I have refrained from using aprotinin. ${ }^{24}$ That report, at least, shows that there has been increased incidence of renal failure with aprotinin. Again, something that we do routinely is to tell the perfusionist to maintain a higher perfusion pressure during cardiopulmonary bypass. It would have been nice to have definitive data to show what that pressure should be and in the event that those pressures were not maintained if those patients suffer adversely from increased risk of renal complications postoperatively. 
Dr Thistlethwaite. Was intra-aortic balloon pumping used in any cardiac operations on kidney transplant patients? If so, from which groin side was it placed? Was the fate of the allograft different in any of these cases?

Dr John. Good question. It is something that we did not look at but probably should.

Dr Thistlethwaite. Finally, when a valve replacement needs to be performed in a patient with a kidney or liver transplant that will require allograft biopsy in the future, what kind of valve do you select and how do you manage their warfarin sodium (Coumadin)?

Dr John. I would treat that as I would with a nontransplant recipient, again presenting the risks and benefits of a tissue versus a mechanical valve. With increasing data that the tissue valves have a longer freedom from degeneration as compared with 10 years ago, I now favor the use of tissue valves in renal transplant patients to obviate the bleeding complications of biopsies and the other adverse effects of warfarin. I would clearly recommend the use of a tissue valve in these patients.

Dr David Follette (Sacramento, Calif). I too enjoyed your presentation. I am still bothered by the fact that you included patients with failed renal allografts in your analysis. The real question is, in patients with functioning transplants, does cardiac surgery have an adverse effect on those transplants? Those patients were all receiving dialysis. Even if they were on a low dose of immunosuppression, at least the way my anticipation in reading your abstract was, I wanted to know what happened with patients who had transplants and you reduce your $\mathrm{n}$ size down to 40 from 70. Perhaps you could tell us in a little bit more detail why you included patients who had failed transplants in your analysis.

Dr John. It was something that we grappled about and we finally decided to include them. As you know, most if not all of these patients are on immunosuppression. I was initially surprised that patients with failed allografts are on immunosuppression, and the reason that I obtained on discussion with one of the renal transplant physicians was twofold. One is that the presence of immunosuppression in a patient with a failed renal allograft will prevent the development of anti-HLA antibodies. Their development would be a contraindication for a second renal transplant, which is always considered in a patient with a failed allograft. The second reason for having maintenance immunosuppression even though they have chronic failed grafts is to prevent the occurrence of acute rejection, which can still happen in a failed organ. An acute rejection could make these patients especially sick. For both of these reasons they are on maintenance immunosuppression. That is why we included patients with failed allografts with the renal transplant. The good news is that even if we took that away, the message is still the same. The operative mortality is low and morbidity is comparable except for a higher incidence of renal dysfunction. Those were the reasons that we clumped them together.

Dr Michael Davidson (Boston, Mass). Given your excellent results and also your large patient population, I would be interested to know whether there are any plans to do any kind of comparison between surgical revascularization as you have done and percutaneous revascularization. That might be an interesting question in terms of how these patients fare with percutaneous coronary interventions, not only in terms of their transplant but also in terms of what their revascularization success is over time comparing surgical versus percutaneous in this particular patient population.

Dr John. I will answer that very briefly. It is hard to make a comparison from this study. About $40 \%$ of our patients who underwent $\mathrm{CABG}$ with a renal transplant had previous coronary interventions. From the larger United States Renal System database, even though the initial operative mortality was higher in renal transplant patients than in those with percutaneous coronary intervention, longterm survival was significantly better with surgical revascularization. 